\title{
Towards Answering, What Do We Know about Elementary Pre-Service Teachers' Noticing Skills in Science? A Pre-Requisite to Prepare Them to Teach Responsively in Science Classrooms
}

\author{
Tejaswini Dalvi, Anna Hofmann \\ Department of Curriculum and Instruction, Centre of Science and Math in Context, University of Massachusetts, Boston, USA \\ Email: Tejaswini.Dalvi@umb.edu
}

How to cite this paper: Dalvi, T., \& Hofmann, A. (2019). Towards Answering, What Do We Know about Elementary Pre-Service Teachers' Noticing Skills in Science? A Pre-Requisite to Prepare Them to Teach Responsively in Science Classrooms. Creative Education, 10, 332-352. https://doi.org/10.4236/ce.2019.102027

Received: November 13, 2018

Accepted: February 18, 2019

Published: February 21, 2019

Copyright ( 2019 by author(s) and Scientific Research Publishing Inc. This work is licensed under the Creative Commons Attribution International License (CC BY 4.0).

http://creativecommons.org/licenses/by/4.0/

\section{c. (i) Open Access}

\begin{abstract}
A teachers' ability to notice and analyse the substance of student thinking, is an important feature of effective science teaching. To prepare new science teachers to attend to students' thinking, it is important for teacher educators to first understand what novice teachers notice in science classrooms, what they associate with the idea of noticing and in what ways their noticing skills can progress. To study novice teachers' noticing abilities, our study employs two different assessment tools, an open noticing assignment and a focused noticing task as pre and post assessments during a semester long science methods course. We report on a variety of noticing themes that highlight a wide variation in what the novice teachers perceive as important to notice in science classrooms. Pre-post analysis of these noticing themes suggests a shift in noticing from general classroom aspects towards noticing science specific aspects as science topics or concepts being discussed and students' ideas about those. Using a mixed methods analysis lens for both tools, we present various sophistication levels of teacher noticing. These levels not just serve as an indicator of the PSTs' noticing skills but also as a framework for educators to help PSTs develop responsive teaching strategies in elementary science classrooms.
\end{abstract}

\section{Keywords}

Teacher Noticing in Science, Pre-Service Teacher Education,

Elementary Science Education, Responsive Teaching in Science

\section{Introduction and Rationale}

An important feature of effective science teaching is the teachers' ability to at- 
tend to student thinking (Berland \& Riser, 2009; Windschitl, Thompson, \& Braaten, 2011). The practice of attending to student thinking, positions student ideas to form basis of meaningful learning in classrooms. It requires teachers to attend to student thinking in ways that it could contribute to scientific sense making and knowledge building while avoiding the pitfalls of viewing students' science ideas as "correct" or "incorrect" (Coffey, Hammer, Levin, \& Grant, 2011). To support students' ideas and channel them towards knowledge building, teachers need to acquire a skill set that includes learning to notice, analyze and then respond to student ideas. The practice of attending to student thinking is an essential step towards moving away from the static view of teaching science as delivering facts and information. Rather develop an evolved view of teaching and learning science as facilitating active student engagement in the scientific sense making process. Being able to notice and analyze student ideas is a pre-requisite to be able to respond to them and is deemed essential to responsive teaching in science classrooms (Levin, Hammer, \& Coffey, 2009). We draw from Robertson, Scherr and Hammer's (2015) views of teacher noticing as "a stance towards student ideas" and focus on noticing and analyzing skills in science classrooms specific to student thinking. Learning to notice is, however, not obvious (Ball, 2011). The skills of noticing, analyzing and responding to student ideas, demand know-how of scientific disciplinary knowledge (McNeill, 2009; Zangori, Forbes, \& Biggers, 2013), content knowledge for teaching and pedagogical content knowledge (Ball, Thames, \& Phelps, 2008). Also, an understanding of what it means to notice student thinking and its purpose is essential to its implementation in classrooms and requires significant training and support.

The demands and challenges around learning to notice, point to the benefits of early career training for new teachers. Levin, Hammer, \& Coffey (2009) in study of responsive teaching reveals that when trained and encouraged, even novice teachers can attend and respond to student thinking as it plays out in a classroom. Their study emphasizes the need for scaffolds to help teachers develop skill set essential to be able to attend to student thinking.

We hypothesize that to support and effectively prepare teachers, educators need to understand what novices associate with the idea of noticing, what they notice and in what ways their noticing skills can progress. This can potentially enhance the science noticing framework for novice teachers learning and help teacher educators make informed decisions around preparing new elementary teachers of science to adapt instructions in response to student thinking. Teacher training programs offer an ideal site for studying early noticing practices of novice teachers and provide support for teachers early in their career to develop skills of noticing. In light of the arguments presented above, we propose to investigate the following research questions:

1) What do elementary pre-service teachers perceive as essential or important to notice in science classrooms?

2) To what extent and how, do pre-service teachers develop expertise in no- 
ticing skills?

Our study attempts to understand pre-service teacher noticing skills in science classrooms and hence advance responsive teaching practices. To situate our study, we first present the theoretical framework of responsive teaching, teacher noticing and use of videos in teacher education that provide the guidance frames for our study. Next, we present the study design that includes the study context, participant details and the tools employed for the data collection. This is followed by our results and discussion section. We conclude with limitations and potential implications of our study.

\section{Theoretical and Empirical Foundations}

Science education reforms and the hence proposed new science standards (NGSS Lead States, 2013) call for student engagement in the eight practices of science and engineering, that include some as asking questions, developing and conducting investigations and constructing scientific explanations towards effective participation in science inquiry. The eight practices are proposed to mediate active student engagement in sense making and knowledge building to engage in science inquiry (Schwarz, Passmore, \& Reiser 2017). To facilitate meaningful student engagement in these practices, it is essential that teachers attend to students' thinking as it evolves in a classroom. The instructional support required needs to prioritize student ideas. Responsive teaching is an instructional strategy that involves shaping instructions in response to students' thinking during inquiry (Hammer, Goldberg, \& Fargason, 2012; Levin, Hammer, Elby, \& Coffey, 2012; Maskiewicz \& Winters, 2012) and hence has the potential to address the new demands. The strategy prioritizes paying attention to student thinking and then developing instructional moves based on it in ways that would facilitate the coordination of 1) engaging students in the pursuit of an explanation of a phenomenon and then 2) supporting them in their pursuit (Hammer, 1997). Responsive teaching involves adapting teaching plans and objectives within a lesson while working towards larger learning goals. And hence the strategy and the required set of teacher practices differ from conventional practices of lesson planning that first give attention to the established body of knowledge.

In our study, we draw on the responsive teaching framework, the essence of which is noticing student thinking. Noticing is valuable because it is the first step in interpreting student thought and appropriately responding to it. Effective noticing skills allow teachers to better understand student thinking and cater the curriculum to progress scientific inquiry. It forces teachers to develop an evolved stance towards students thinking and do things differently, rather than following an established set of instructional plans. The ability to notice student thinking is an important characteristic of teachers' professional vision (Sherin \& Van Es, 2009). Developing a professional vision for teachers involves using an evolved lens to "see" how a lesson is progresses, interpret student ideas during instruction and further make pedagogical decisions during instruction (Sherin, 2001, 2007).

Teacher noticing and responding does take effort and reflection, which maybe 
a potential reason for its infrequent implementation (Hammer et al., 2012; Van Es \& Sherin, 2008). Recognizing the importance and the challenges of teacher noticing, many researchers have focused on examining different aspects of in-service teacher noticing (Borko, Jacobs, Eiteljorg, \& Pittman, 2008; Jaber, 2014; Jacobs, Lamb, \& Philipp, 2010). Sherin and Van Es (2009) study the use classroom videos with mathematics teachers to support them in learning to notice. Their study discusses the importance of helping teaching teachers identify what is important to identify in a teaching situation, make connections between specific events and broader principles of teaching and learning and to use what one knows about the context to reason about a situation. Studies have also explored teachers' noticing of students' science ideas and its' alignment with canonical disciplinary knowledge (Black, Harrison, Lee, Marshall, \& William, 2003; Covitt, Caplan, \& Cano, 2018; Furtak, 2012; Furtak \& Heredia, 2014). Though we recognize the value of these studies, we consider that to support responsive teaching in science classrooms, it's essential to move away from just aligning student ideas with disciplinary knowledge. Often this practice leads to teachers categorizing student science ideas or responses as "correct" or "incorrect" and that in turn restricts them from attending to the substance of student thinking. Similar studies on teacher noticing have reported improvement in teachers noticing skills, progressing from descriptions and evaluations, to making at least some call-outs and connecting them to teaching principles with evidence (Van Es et al., 2017; Van Es \& Sherin, 2008; Van Es \& Sherin, 2002; Van Es \& Barnhart, 2015; Luna et al., 2018). This progression is however closely tied to careful scaffolds provided to the teachers either through courses, discussions, software, videos, etc. (Van Es et al., 2017; Van Es \& Sherin, 2008; Van Es \& Sherin, 2002). We found that most reported studies insist on various forms of scaffolds to support teacher reflection on their noticing and interpretation of student thinking.

Studies that focus on pre service teachers, characterize novice teacher noticing skills when they examine student work (Luna, Selmer, \& Rye, 2018), other teacher's instruction (Mitchell \& Marin, 2015; Star \& Strickland, 2008; Talanquer, Tomanek, \& Novodvorsky, 2013) or analyze videos of their peer teaching rehearsals (Benedict-Chambers \& Aram, 2017) to help novice teachers notice issues of practice related to ambitious science teaching (Lampert et al., 2013). For novice teachers, who are still developing their understanding of teaching practices, pedagogical and content knowledge for teaching and classroom management, learning to notice, is definitely not obvious. It calls for scaffolds to help pre-service teachers develop noticing skills as well as understand the purpose of noticing. And for teacher educators hence it is imperative to advance their knowledge and understanding of how to support and train teachers to attend to student thinking.

The field of teacher education acknowledges the role of videos as a helpful tool to support in-service and pre-service teacher learning (Van Es, Cashen, Barnhart, \& Auger, 2017; Van Es \& Sherin, 2008; Van Es \& Sherin, 2002; Levin et al., 2009; Van Es \& Barnhart, 2015; Luna et al., 2018). Videos can be paused, 
re-watched, and rewound to see different interactions taking place in the classroom making them one of the most easily accessible tools to examine teacher noticing (Van Es \& Sherin, 2002). By having a video as opposed to an observer or field notes, teachers can see what is happening through a different analytical lens that can help them better focus on students' content knowledge, their ideas and science practices.

Sherin's work on developing professional vision (2001) uses classroom videos that capture the richness of classroom interactions, to provide teachers with opportunities to observe and reflect on the interactions. The study highlights that participation in video reflection helps mathematics teachers pay close attention to student thinking and reason about what they notice. Several other research groups have also investigated distinct approaches to using student video in pre-service teacher education. VAST (Video Analysis Support Tool), is a software tool designed to provide support to mathematics teachers as they learn to notice and analyze features of classroom interaction (Van Es \& Sherin, 2002; Sherin \& Van Es 2009). The study has reported changes in high school pre-service teachers' skills of noticing and interpretations, over time. Star and Strickland (2008) have administered video-based assessments to pre-service teachers both before and after they completed a secondary mathematics methods course. Their study reported improvements in the PSTs ability to notice features of classroom environment, classroom management, mathematical content, mathematical tasks, and student communication. We draw from these studies to inform the design of our video based assessment tools to unpack PSTs noticing skills in elementary science classrooms.

\section{Study Design}

\section{Context and Participants}

The study was conducted at a large public university with 34 pre-service teacher participants. The participants were enrolled in a graduate level, elementary teacher licensure program. They held bachelor's degrees in a range of disciplines but had limited college coursework in science disciplines. 13 of the pre-service teachers took the science methods class during the spring semester while the remaining 21 took the same course in the following fall semester. We refer to this combined group of participants as the pre-service teachers, or "PSTs". The structure for the semester long science methods course and the instructor (the first author) was the same for both semesters. The science methods course explores theoretical and practical perspectives on teaching elementary science and engineering in grades one to six. It aims to enable participants to create classroom environments that promote inquiry and design, and make science and engineering accessible to all students.

The data for this study primarily came from two different assessment tools, a) open noticing assignment, and b) focused noticing task, both administered at different points during the science methods course. Below, we present an over- 
view of the two assessment tools, its administration and data analysis techniques used.

\section{Tools}

1) Open Noticing Assignment

The Open noticing assignment was administered in class at two different points of the methods course. It was first administered as a pre-course task and then later during the last session of the course. For the assignment the PSTs first watched a classroom video from a published source, and then respond to specific prompts. A transcript was given to the PSTs before they saw the videos. They could take notes, if needed. The video focused on whole class student discussion around a science concept. Though the discussion was teacher facilitated, it was not teacher led. After watching the video the PSTs responded individually to the question, what do you notice in this science classroom? The question was open ended because we wanted to get an unbiased response to help answer our first research question of what PSTs think is important to notice. Next, the teachers were asked to identify instances from their noticing, where students might need support and suggest immediate moves or scaffolds to respond to students' thinking. The purpose of this assignment was to train novice teachers to notice the substance of students' thinking and further help them respond to their thinking by providing suitable scaffolds. For the purpose of this study, we focus only on PST responses to the first question. In between the two assessment points, the instructor included a session on responsive teaching that was based on a modified and condensed version of the responsive teaching in science free online PD resources.

To analyze the open noticing assignment data, first we de-identified all the PST responses. The pre and post responses were combined randomly on a master sheet and assigned a unique numeric code. For the first around of analysis, two researchers independently analyzed the data. The focus of this first round of analysis was to identify what the PSTs pay attention to in a science classroom. The researchers categorized the responses in different themes in order to capture the essential aspects of PSTs noticing. Next, we compared the theses, looking for similarities that we decided to keep. We discussed the differences found and consolidated them into a new set of themes. With this, we had a consolidated set of categories or themes of what PST notice with definitions and examples that fell into each. The two authors of the paper did the primary analysis. For the next round of analysis, a different researcher analyzed the data along with the first two. We once again independently analyzed the data against our noticing themes using its definitions. The entire set of data was coded, and we found an overall 93\% inter-rater reliability amongst the three researchers. For any conflicts, we revisited the responses and agreed on the themes they should fall in. At this point no new themes were added. Rather, adjustments were made to the theme definitions to better convey the meaning. Table 1 , in the results section presents these themes. These themes and the pre-post patterns in them, help 
Table 1. PST noticing themes with corresponding description and examples.

\begin{tabular}{|c|c|c|}
\hline Teacher Noticing Themes & Description & Examples of PST responses \\
\hline $\begin{array}{l}\text { A. Student behavior and } \\
\text { classroom management }\end{array}$ & $\begin{array}{l}\text { PST response includes student/s classroom behavior (how } \\
\text { students talk and behave) and/or classroom setting as } \\
\text { whole group settings, small group settings. }\end{array}$ & $\begin{array}{l}\text { 1. Whole class discussion; students talking. } \\
\text { 2. Students talking over each other, no } \\
\text { classroom expectations around sharing. }\end{array}$ \\
\hline \multirow[t]{3}{*}{$\begin{array}{l}\text { B. Teacher facilitation and } \\
\text { attitude }\end{array}$} & $\begin{array}{l}\text { a. PST response includes teacher moves or teacher } \\
\text { facilitation. The response may or may not critique the } \\
\text { teacher move as good/bad. }\end{array}$ & $\begin{array}{l}\text { 1. Teacher promotes student agency in talk. } \\
\text { 2. The teacher is good at controlling students } \\
\text { during group discussions. }\end{array}$ \\
\hline & $\begin{array}{l}\text { b. PST response includes a suggestion for potential } \\
\text { teacher moves. }\end{array}$ & $\begin{array}{l}\text { 1. Teacher should make them listen to each } \\
\text { other respectfully. }\end{array}$ \\
\hline & $\begin{array}{l}\text { c. PST response includes a comment on nature of teacher } \\
\text { attitude. }\end{array}$ & $\begin{array}{l}\text { 1. Teacher is laid back. } \\
\text { 2. Teacher seems relaxed. }\end{array}$ \\
\hline C. Gender dynamics & $\begin{array}{l}\text { PST response includes a description of the observed } \\
\text { gender based participation in the classroom and/or makes } \\
\text { a suggestion for the same. }\end{array}$ & $\begin{array}{l}\text { 1. Boys are talking more and the girls don't } \\
\text { seem interested. } \\
\text { 2. Girls should be encouraged to participate. }\end{array}$ \\
\hline \multirow[t]{2}{*}{ D. Student ideas } & $\begin{array}{l}\text { a. PST response includes a direct quote where the student } \\
\text { expresses her/his science ideas OR the corresponding } \\
\text { line numbers from transcript. }\end{array}$ & Line 23 , student is talking about her ideas. \\
\hline & $\begin{array}{l}\text { b. PST response includes a rephrased version of the } \\
\text { student science ideas. }\end{array}$ & $\begin{array}{l}\text { Student uses the analogy of penguins sticking } \\
\text { to each other to explain the state of ice } \\
\text { molecules. }\end{array}$ \\
\hline \multirow[t]{2}{*}{$\begin{array}{l}\text { E. Critique of student ideas } \\
\text { without reasoning }\end{array}$} & $\begin{array}{l}\text { a. PST response includes a critique of a student idea as } \\
\text { complete/incomplete or correct/incorrect however } \\
\text { without any reasoning for the critique or any } \\
\text { elaboration on student ideas. }\end{array}$ & $\begin{array}{l}\text { 1. Student A expresses his ideas but they are } \\
\text { incorrect. } \\
\text { 2. Student B has correct science ideas about } \\
\text { water cycle. }\end{array}$ \\
\hline & $\begin{array}{l}\text { b. PST response includes a comment on nature of } \\
\text { students' participation (frequency of their participation } \\
\text { or quality of their language used). }\end{array}$ & $\begin{array}{l}\text { 1. Student B shares lot of ideas. } \\
\text { 2. Student A uses good terminology. }\end{array}$ \\
\hline \multirow[t]{2}{*}{$\begin{array}{l}\text { F. Make sense of student } \\
\text { ideas }\end{array}$} & $\begin{array}{l}\text { a. PST response includes an attempt to describe the } \\
\text { student ideas about a topic. }\end{array}$ & $\begin{array}{l}\text { Student is describing the motion of the top. She } \\
\text { is trying to use science terms as "force" to } \\
\text { describe the motion. }\end{array}$ \\
\hline & $\begin{array}{l}\text { b. PST response includes an attempt to describe the } \\
\text { student ideas about a topic and further critiques it as } \\
\text { correct/incorrect or complete/incomplete. }\end{array}$ & $\begin{array}{l}\text { Student A is trying to explain the motion of a } \\
\text { top by comparing it to an old man. He is able } \\
\text { to use the analogy to correctly describe the } \\
\text { observed motion of the top. }\end{array}$ \\
\hline \multirow[t]{2}{*}{$\begin{array}{l}\text { G. Overarching science topic } \\
\text { or science discipline }\end{array}$} & $\begin{array}{l}\text { a. PST response mentions the overarching or central } \\
\text { science idea. }\end{array}$ & The class is discussing water cycle. \\
\hline & $\begin{array}{l}\text { b. PST response only mentions a specific discipline or a } \\
\text { science word. }\end{array}$ & $\begin{array}{l}\text { 1. Physics, science, math } \\
\text { 2. Students used the physics words like force, } \\
\text { friction, etc. }\end{array}$ \\
\hline
\end{tabular}

answer our first research question.

\section{2) Focused Noticing Task}

The focused noticing task is based on the video case diagnosis (VCD) task, a 
quantitative assessment tool to map the evolution of PSTs engineering teaching responsiveness (Dalvi \& Wendell, 2017).

The VCD task involves the PSTs first watching a student video. This video focuses on students engaged in solving a design challenge with minimum adult intervention. The videos are usually $5-6$ minutes in duration. The PSTs are given a transcript before they see the videos and can take notes on it as needed. Next, they are given 30 minutes to respond to a questionnaire. This questionnaire asks them to list a) student science ideas they notice, b) students' engineering practices, and then asks them to c) suggest teacher moves to help develop student ideas and practices. The VCD was administered as pre and post assessment tool, on the first and the last day of the course. The student responses were graded as per the rubric developed as part of a previously published study (Dalvi \& Wendell, 2017) where a PST response for noticing student ideas could score between one-four points based on completeness in noticing the science idea. For the purpose of this study and the focused noticing task, we focus on student responses only to the first part of the questionnaire that asks the PSTs to list any students' science ideas they notice in the video and provide evidence for it.

The focused noticing task differs from the open noticing assignment in two important ways. First, both the tasks present PSTs with different classroom situation to analyze. The focused noticing task uses videos of small groups of students working to solve an engineering design challenge. The videos do not include any adult/teacher intervention. Whereas the open noticing videos include whole class discussion sessions around a science concept or phenomenon facilitated by the teacher. Secondly, the open noticing assignment asks the PSTs an open-ended question, what do you notice in the science classroom in the video? On the other hand, the focused noticing task asks the PSTs to list students' ideas of science that they notice. The specific nature of this question directs the PSTs to notice students' science ideas. While the open noticing responses helps us identify how PSTs prioritize noticing in science classrooms, the focused noticing task gives us an insight into what the PSTs interpret as students' science ideas. Together, we believe the tools would help us unpack the early noticing and interpreting habits of novice teachers in science classrooms and help answer the second research question.

\section{Results and Discussion}

In this section, we present our results from the two assessment tools, open and focused noticing, followed by discussions around it. We believe this way of presentation will better convey our ideas. We share our results in the same order that we analyzed data.

\section{Open Noticing Assignment}

To answer our first research question, we first present the various PST noticing themes and then the shifts we observed in these themes from pre to post. 
1) Our analysis of this task presents various noticing themes that capture what novice teachers deem as important to notice in the science classroom. Table one includes six major themes and sub themes of novice teacher noticing, a description for each theme and examples for each.

2) The shift in PSTs noticing themes over time.

Here we present pre-post analysis of PST responses that captures a shift in PST's noticing skills. Figure 1 shows the number of PST responses that fall in each theme for pre and post task. To share our results, we discuss the shift from pre to post for each of the noticing themes.

- Theme A. Student behavior and classroom management.

Figure 1 indicates that for the pre-course task, 19\% of the teacher responses fell into this theme, making this as one of the most prominent noticing themes for PSTs. The noticing frequency however drops to $3 \%$ for the post course task. The beginning of the course when this task was administered the PSTs are in their first semester of the graduate licensure program and also the start of their in-school practicum experience. Also, other course work during this introductory semester is highly focused on student classroom behavior, classroom environments, and classroom management. For most students enrolled in this program with limited exposure to science, this is their first formal classroom experience as a science teacher or observer. The classroom settings, student behavior and aspects of classroom management, are the few immediate observable things for these novices. These might be potential reasons for prominent contribution to this theme for the pre-course task. However, training in science methods, sustained experiences in classrooms, focused sessions on responsive science teaching during science methods course, may be responsible for PSTs shift in focus towards the end of the course where the contribution to this theme significantly drops.

- Theme B. Teacher facilitation and attitude.

This theme has three subcategories, a) noticing what the classroom teacher

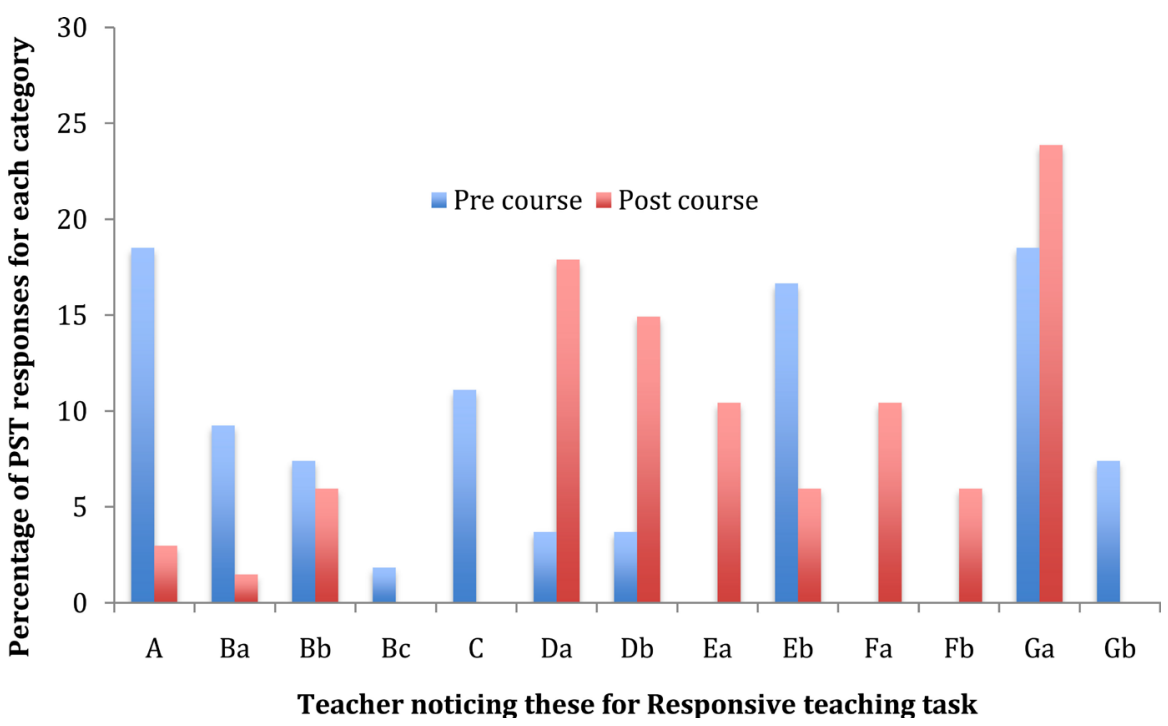

Figure 1. Graph representing a pre-post shift in PST noticing themes. 
does (how they facilitate, what they say), b) making suggestions for potential teacher moves and c) noticing teacher attitude, how they appear (example: laid back). For the pre-course task, a total of 19\% PST responses fall in this theme with $\sim 9 \%$ of PSTs noting what the teacher does (category a), $7 \%$ of the PSTs suggesting teacher moves (category $b$ ) and $2 \%$ of the PSTs noting teacher attitude (category c). For pre course, this theme is still one of the most prominent themes with PSTs focusing on the "teacher" in science classrooms. Also, none of the noticing aspects focus on or point to any science specific teacher facilitation. For the post course task, the overall contribution to this theme falls to 7\%. For post course, very few ( $1.4 \%$ responses) PSTs notice what the teacher does (facilitation) in the video. And none of the PSTs point to the classroom teacher attitude. The major contribution to the post course comes from PSTs attempting to suggest potential teacher moves ( $\sim 6 \%$ subcategory $b$ ).

The overall drop in responses for this theme may suggest that the PSTs are shifting focus away from the teachers. This is essential towards developing a stance where PSTs learn to pay attention to students' ideas. Still majority of post course responses for this theme indicate that even when asked to notice, PSTs suggest potential teacher moves and are make suggestions for improvements. This may indicate that the PSTs try to notice for instances where better scaffolds are required for student learning or realize the potential purpose of noticing. However an understanding of what is important to notice in science classroom is not obvious.

- Theme C. Gender dynamics.

The figure indicates that for pre-course task, $11 \%$ PST responses fall in this theme. PSTs attention to gender specific participation may indicate that they are aware and sensitive towards the need for girls to participate more in science classrooms. However, for post-course task, none of the PST responses fall in this theme. This may seem like a disturbing result with equity in science classrooms being an important aspect that needs teacher and educator attention. However, the task asked PSTs for the most important things they noticed in science classroom, and this was after focused training to guide them to pay attention to students' thinking, ideas and making sense of what they say throughout the science methods course. Given this, we believe, it is valid to see this shift in PST noticing.

\section{- Theme D. Student ideas.}

This theme has two subcategories, a) noting direct quotes of student talk or corresponding line numbers from the transcript and b) including rephrased version of student ideas. For pre-course task, a total $7 \%$ of PST responses fall in this category, with almost equal contribution from each of the two subcategories. The pre-course task shows a very small number of PSTs paying noticing the student ideas that includes either direct quotes of student talk or corresponding line numbers from the transcript or rephrased student ideas. However, contribution to this theme significantly increases to $33 \%$ for the post-task. There is a 
considerable increase in PSTs noticing of student ideas, both in stating direct quotes (subcategory a $(\sim 18 \%)$ ) and rephrasing student ideas (subcategory b $(\sim 15 \%))$. This indicates that for novices, paying attention to what students' say or student ideas is not an obvious. However with training and support, more PSTs are shifting their focus away from other classroom aspects and focusing more on students and are paying attention to students' ideas. We realize, that this is not enough evidence to say that they attend to substance of student thinking, however the PSTs do focus on what the students say, student ideas and hence show their readiness to further analyze student thinking.

- Theme E. Critique of student ideas without reasoning.

This theme has two subcategories, a) PSTs critique a student idea without any reason for their critique and b) PSTs comment on nature of student participation. For the pre-course task, entire contribution of $16 \%$ for this theme comes from subcategory b. Although the PSTs notice student participation in discussions they do not elaborate on student science ideas or what they say (related to science). For post task however there is a drop in the number of PST responses that comment of nature of student participation $(5 \%)$. And we observe that now there are $10 \%$ of PST responses that also fall into the subcategory a. Here the PSTs critique a student idea as complete/incomplete or correct/incorrect however without any reasoning for the critique. Either does not indicate PSTs unpacking the substance of student thinking, however they take notice of what the students say or their ideas. The shift in noticing where the PSTs are starting to focus on what students say rather than how frequently they say something or quality of language they use, for this theme could be taken as the PSTs beginning of learning to focus on student ideas.

- Theme F. Make sense of student ideas.

This theme has two subcategories, a) PST attempts to explain or elaborate on students' science idea and b) PST attempts to explain students' science ideas and further critique it as complete/incomplete or correct/incorrect. For pre-task, none of the PST responses fall in this theme. This drastically changes for the post task with a total of $16 \%$ of PST responses falling in this theme. Out of those, $10 \%$ fall in subcategory a, while $6 \%$ responses fall under b. The significant shift in PST noticing from pre to post task, is evidence that PSTs can pay attention to student ideas and make an attempt to make sense of those ideas. It indicates the ability of PSTs to develop essential noticing skills to support students' participation in scientific sense making and knowledge building.

- Theme G. Overarching science topic or science discipline.

This theme has two subcategories, a) PST response mentions the overarching or central science idea and b) PST response mentions a specific discipline or a science word they hear in the video. The figure one shows that most responses both for pre (approx. $26 \%$ total: $18.5 \%$ for a, and $7.4 \%$ for b) and post ( $24 \%$ all for a) tasks fall into category. For the pre-course task, $7.4 \%$ of PST responses mention a science discipline (example: physics) or provide isolated science 
words they notice in the video. There is however, a complete drop observed during the post-course task for this sub category. The entire contribution for post-course task to this category comes from a, where PSTs notice and mention the overarching science topic, central to the discussion in the video. This change suggests that specificity in noticing skills is increasing through the course.

The overall pre-post analysis for what the PSTs deem as important to be noticed in science classrooms, reveals a shift in the focus of PST's noticing towards students' ideas. Figure 1 shows higher frequencies for theme A, B, C and G for pre-course that affirms that paying attention to student ideas and making sense of those is not an obvious skill for novice teachers. Furthermore these themes present an elaborate scenario of what are the aspects that PSTs readily notice. At the same time Figure 1 highlights a shift in PSTs noticing with higher post course frequencies for themes D, E and F, all focused on students' ideas. Each of those themes and their subthemes capture differences in quality of PST noticing about the students' ideas. Specifically, the extent to which the PSTs make sense of what the student is saying and evaluation of it contributes to meaningful science learning. The variation observed in the categories also brings to our attention a) the PSTs use different lenses to look at student ideas. Noticing student ideas could mean noticing what the student literally says, hearing any relevant content specific word that a student uses, or noticing student participation or the overall science topic being discussed in class. b) That the initial naïve lens being exhibited through the pre-course task evolves into a sophisticated lens for student noticing that focuses more on evaluating the essence of student thinking.

\section{Focused Noticing Task}

The focused noticing task requires the PSTs to list science topics and student ideas about those topics that they notice. It is important to state that the tool does not evaluate a PSTs ability to look for alignment of students' science ideas with the disciplinary knowledge. Rather, our intent is to explore how PSTs make sense of students' science ideas. We analyzed the PST responses to look for how they notice students' science ideas and to what extent they attempt to analyze those. And further study corresponding shifts in those from pre to post.

Figure 2 shows the percentage of PST responses for each score for both, pre and post tasks and a significant shift in percentage of responses for each score. During the pre-course assessment, 33\% of the PSTs who scored zero either did not respond or stated names of broad fields of science, such as physics or chemistry. This may imply that PSTs may be confusing the term science ideas for science sub-disciplines like physics. Although it is not incorrect to point to a specific sub-discipline, in the given context of the question asked, it may point towards PSTs insufficient understanding of what is meant by the term science idea/s. For pre-course, a majority of PST responses (47\%) score 1 point. PST responses with a score of one point include relevant science topics discussed in the video, but do not include any student ideas about the topic. For example listing magnetism as the science topic. The frequency analysis tells us that most 


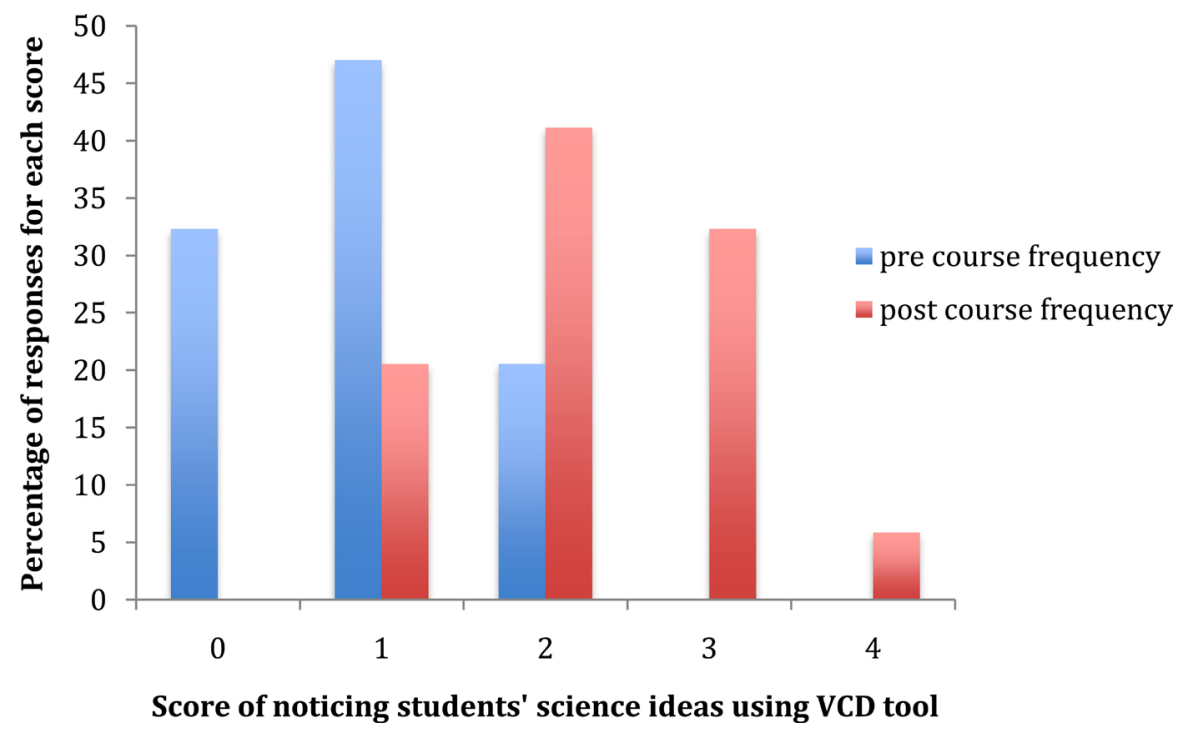

Figure 2. Graph representing pre-post score shift for focused response task.

PST responses fall under this score category. This indicates that most PSTs can isolate the overarching important science ideas, such as magnetism or gravity, as discussed by the students. The highest score achieved for the pre-course responses is two with $21 \%$ of PST responses. PST responses with a score of two points include a science topic and a partial expression of students' ideas about the topic. For example, a response lists magnetism and includes the terms, magnets-repulsion-attraction. The PST response does not fully capture the students' ideas about the topic. A full or a complete description of a students' science idea includes an attempt (may be accurate or inaccurate) at a causal explanation OR an observation of a phenomenon OR inference about a phenomenon or behavior OR a description of how something works. However, it indicates that the PSTs isolate science topics and also notice certain science ideas about the topic being discussed by the students. At this point in the course, none of the PSTs fully described any students' science ideas.

This score scenario significantly changes for the post course assignment. None of the PST responses score a zero. This may suggest that more PSTs are accurately responding to this part of the questionnaire with their noticing ability going beyond mentioning sub-disciplines of science. PSTs, at this point, identify the overarching science topic or the central science ideas that are discussed in the student video. A majority of the responses (41\% with a score of 2 ) include the specific science ideas being discussed and some description of the students' ideas about it. We also note that at this point, $32 \%$ of PST responses scored a three and a small yet a certain percentage (6\%) of responses scored a four. A response with a score of three points includes science topic and at least one fully stated student science idea and a score of four points includes science topics and two fully stated science ideas. This significant shift in scores during the post-course task highlights PSTs evolved understanding of the term science ideas and their readiness to notice students' science ideas. And their detail articulation of stu- 
dents' at least one science idea emphasizes an evolved sense of noticing in science classrooms where they go beyond what is literally said and attempt to makes sense of what the students say or what their ideas are.

To statistically assess the variation across the two points, pre and post methods course, we used paired t-tests to compare individuals' performance. We report an increase in their average total score on the $\operatorname{VCD}\left(\mathrm{M}_{\text {pre }}=0.88 ; \mathrm{M}_{\text {post }}=\right.$ $2.24 ; \mathrm{t}(33)=9.7140 ; p<0.0001)$ that shows a significant shift in PSTs noticing of students' science ideas after their participation in the science methods course.

\section{A Combined Lens to Track Evolving Stages of PST s Noticing Skills}

In this section we simultaneously analyze the pre-post results from both the tools to help answer our second research question to discuss the possible evolution in PST noticing skills.

Qualitative analysis of open noticing task responses reveals a wide range of PSTs noticing themes as well as a shift in those from pre to post task. The most prominently occurring themes for pre-course suggest that the PSTs were more focused on noticing student behavior and classroom management, gender dynamics, central science topic being discussed and that they focused on quantitative nature of student participation like how often a student said something with no focus on what the student said. The most prominent noticing themes for post course task include, noticing student ideas, noticing science ideas, critiquing student responses and making sense of student ideas. This indicates a shift from noticing more general classroom aspects to noticing science specific aspects of a classroom as science ideas being discussed and students' science ideas. Also, the focused noticing task analysis reveals a significant positive shift in PST's noticing of students' science ideas that inform us that with scaffolds PSTs can more fully understand and make sense of students' ideas during discussions. Results from both tools suggest an evolutionary trend in PSTs ability to attend to student thinking in science classrooms that is essential to teaching responsively. To better understand this trend or progression we simultaneously analyze the results of the two noticing tasks.

We first created a pre-course profile of each PST to include their open and focused noticing task scores and also the noticing themes their open noticing task responses fell in. Next, a post course profile was created to include the same for each PST. For a significant (85\%) number of these profiles, we found that PSTs with same scores on focused noticing task had their responses for open noticing task, fall in the same category of noticing themes. For example, for pre-course profiles, all PSTs with a score 1 on VCD, noticed student behavior, teacher attitude and gender-based participation in their RT responses. None pointed to any student ideas or science concepts.

Analysis of the open response task noticing themes corresponding to their focused response task scores in an increasing order, across pre and post, revealed patterns across noticing themes. Also, majority of PSTs with a score 1 for focused noticing task (pre and post), had their open noticing task responses fall under same themes. We organized these observed patterns in themes in an in- 
creasing order of focused noticing task scores across pre and post. The various levels in order exhibit possible stages of sophistication in PSTs noticing skills in science classroom, essential to engage in responsive teaching. Table 2 presents the various levels of sophistication in noticing and include PST noticing characteristics for each to include what the PSTs at that level pay attention to and do not pay attention to in science classrooms.

We do not claim these levels to indicate a generalized progression in PSTs noticing skills. Nor do we claim that a PST's noticing will always follow this specific linear pattern. We present these levels in an increasing order of sophistication (beginning to expert) that is essential for teachers to develop to be able to adapt instructions in response to student thinking. A PST's beginning thinking can fall into any level of sophistication. Also, it is not necessary that the individual PST's progress in noticing will follow each and every step of our levels. However, it may inform us of a possible way in which PSTs or novice teachers can develop their noticing skills. These levels can serve as an indicator of the PSTs' noticing skills. And can potentially help teacher educators understand the PSTs' abilities and help provide appropriate scaffolds responsively.

With increasing sophistication, we first observe that the focus of PST's noticing shifts from teachers to students. Next, the PSTs begin to look at the "how" (how often) of student participation rather than the "who" (if it's a girl or a boy). They also begin to look for science ideas being discussed. As we move to the higher level three, there is a definite focus on students and what they say. The PSTs are not just focused on what the students explicitly say but also critique student responses. However, their critique or feedback does not provide support or scaffolds for learning. At the same time, it informs us of the PSTs possible attempts at evaluating student responses that might indicate the PSTs readiness to

Table 2. PST noticing characteristics for various levels of sophistication in noticing.

\begin{tabular}{|c|c|c|}
\hline \multirow{2}{*}{ Level } & \multicolumn{2}{|l|}{ Pre-service teacher science noticing characteristics } \\
\hline & PSTs focus on & PSTs do not focus on \\
\hline 2 & $\begin{array}{l}\text { Students' classroom participation, literal student responses. Big } \\
\text { science idea/s or overarching science concepts being discussed. }\end{array}$ & Students' and teachers' classroom behavior, classroom norms \\
\hline 3 & $\begin{array}{l}\text { Big science idea/s or overarching science concepts being discussed; } \\
\text { critiquing a student idea as "correct" or "incorrect". }\end{array}$ & The essence of student thinking \\
\hline 4 & $\begin{array}{l}\text { Attending to student ideas by aligning student ideas with } \\
\text { disciplinary knowledge or their content knowledge. }\end{array}$ & $\begin{array}{l}\text { Behavior patterns; classroom norms; categorizing student } \\
\text { responses as correct or incorrect }\end{array}$ \\
\hline 5 & $\begin{array}{l}\text { Making sense of student thinking and then evaluating their } \\
\text { thinking for its ability and appropriateness to contribute to } \\
\text { scientific sense making in the given context of science discussion. }\end{array}$ & $\begin{array}{l}\text { Alignment of student response with scientific know how; } \\
\text { critiquing student ideas as "correct" or "incorrect" }\end{array}$ \\
\hline
\end{tabular}


make sense and evaluate student ideas and perhaps require scaffolds to do so.

We next observe a change and an increase on focus in attending to what students think and evaluating it. We notice a trend in how PSTs evaluate student ideas that we capture as different levels. For level four, the PSTs evaluate student ideas based on their alignment with disciplinary knowledge. For level five that is our most sophisticated level the PSTs evaluate student idea based on its potential to contribute to sense making in classroom science discussions at that moment. For example, a PST at an expert level notices ideas floated around by different students, and attends to a few specific ideas among those which call for attention based on their potential to contribute to scientifically rich and meaningful discussions. These are not necessarily "correct science ideas". Rather, they are ideas that can help students address misconceptions and/ or develop coherent science ideas relevant to the classroom discussion context. By avoiding the pitfall of categorizing a student idea as "correct" or "incorrect", or aligning it with scientifically correct knowledge, the PSTs are learning to effectively notice student thinking, an essential aspect of noticing for responsive teaching. Our data shows that though small, a certain number of PSTs were able to attain this level. This suggests that with proper scaffolds and training, developing sophisticated noticing skills is not beyond the reach of novice teachers (Levin, Hammer, \& Coffey, 2009).

We observe that as we move towards higher levels of sophistication, the PSTs focus less on obvious aspects of students' behavior, classroom norms and movement in and around classroom (Benedict-Chambers \& Aram, 2017). Also, they move away from observing the teacher behavior and facilitation towards focusing more on students. And if they focus on teachers, their focus is on suggesting potential teacher moves in response to what students say. This, we see as an indicator of PSTs beginning to develop responsive teaching skills. For the beginner levels 1-2-3, the focus on teachers and the teacher moves suggested, highlight the PSTs focus on general pedagogical moves and managing student attention and interests. These observations are in line with research work that explores the challenges in developing teachers' ability to notice in productive ways (Borko et al., 2008; Van Es, 2012). For these levels, there is very little PST focus on science content and/or student learning of that science content.

For levels 2 and 3, characterized by PSTs focus on students it is however important to note that the PST responses that include student quotes or it's rephrased versions do not necessarily suggest that they notice students' thinking. This suggests that though these levels shift, as drawn from post-course results, PSTs pay little attention to student thinking (Star \& Strickland, 2008). Hence, it might be noteworthy to present these levels as levels of progression of PSTs noticing. These may form the initial stages of teachers learning to attend to the substance of student thinking.

The relation that we find between the low scores for focused noticing task and limited noticing levels for open noticing tasks, highlights another important as- 
pect for teacher noticing. Elementary PSTs limited science content background (Knaggs \& Sondergeld, 2015) impacts how they make sense of students' ideas. This relation between novice teachers owns science content and their noticing skills, might be a potential reason why not many PSTs attain higher levels of sophistication in noticing.

\section{Limitations}

At this point, we present a few possible limitations of the study and our views on those. First, the methods course included a high emphasis on developing responsive teaching skills within PSTs. Overall the course included dedicated modules and in-class discussions on responsive teaching. And hence, it might not be surprising to see results that suggest a positive shift in PSTs noticing as essential to responsive teaching. At the same time, our study design does not allow us to make direct causal links between the methods course and the test results. The specific aspect that we wish to point to is the diversity that exists in PSTs noticing skills in science classrooms, and the possible levels that they can exhibit with respect to it. An understanding of these levels of PSTs' noticing skills is crucial information for educators to train PSTs noticing skills.

We also recognize that both assessment tools used for this study rely on student videos. PSTs might miss noticing aspects of student thinking or student work on video that they might have seen if they there in the classroom in person. Exclusive use of videos might therefore restrict what they notice. While we recognize this as a possible limitation, we point to and draw from Sherin's study of teachers responding to student videos in the same way they respond to in person classroom situations (Sherin \& Han, 2004). It is also essential to point to the diversity in nature of videos used for the two assignments-one a whole class setting with teacher intervention and the other student design discussions with no adult intervention-this we believe presents teachers with different classroom settings to analyze student work and thinking.

An essential point to recognize is that there was no quantitative data analysis method employed for the open noticing task. And further there was no statistical correlation established between the results for the two tools. However, our primary purpose of using the open noticing task was to look for the quality of teacher responses and the possible range of teacher noticing as a prerequisite for developing responsive teaching skills. Also, our analysis methods employed here does not include looking for a specific change in noticing skills as a result of our methods course. Rather using assessment results from the two tools together to help identify different possible levels of PST noticing skills.

Also, we would also like to state that by no means does our study devalue the role and importance of studying gender dynamics in science classrooms. As stated earlier, an absence in the gender dynamics theme for noticing in the post-test task might be an effect of the emphasis on the student thinking during the course. Also, attending to the two aspects of being productive and being 
equitable in science classroom was beyond the scope of this study that calls for more attention and ability.

\section{Conclusions and Implications}

Understanding the essence of students' thinking and more so their scientific thinking, is a skill to be acquired in order to effectively attend to students' learning needs. This skill is however not obvious for novice elementary teachers. Based on our findings, we draw following conclusions about PSTs noticing skills in elementary science classrooms and present strong implications for teacher educators to support responsive teaching skills in PSTs.

Our study highlights a significant diversity in what PSTs perceive as important to notice in science classrooms. The diversity ranges from obvious aspects, such as classroom behavior, to critical features like substance of student thinking. Even if the PSTs notice students and what students say, there is little focus on the substance of students' thoughts. Their focus on less essential classroom aspects may be a result of their insufficient understanding of the purpose of noticing. Noticing includes listening to and making sense of students' ideas, in order to respond to the ideas with the potential to contribute to meaningful learning, to foster scientific discourse and promote student participation in practices. It would not be without this perspective of noticing that teachers can responsively adapt their instructions to suit students learning (Levin, Hammer, \& Coffery, 2009; Robertson, Scherr, \& Hammer, 2015). And hence, an understanding of noticing as a set of analytical skill set with a purpose of informing one's instructional steps (in the moment or future) is important to be gained by the PSTs.

Previous work on teacher noticing highlights the difficulty teachers face in developing the ability to notice in productive ways (Borko et al., 2008; Van Es, 2012; Benedict-Chambers \& Aram, 2017). Our study, in line with these, further explores the potential reasons behind the challenges faced by novice teachers. Our presentation of the various levels of sophistication in PST noticing, informs teacher educators with a guiding framework to support PST noticing skills. These levels also help provide a shared language around noticing skills for novice teachers. Our study informs us of the different aspects of PST noticing or set of perspectives they hold as they enter formal training. This, we believe, adds to the research knowledge around novice teachers learning to notice. It provides teacher educators with a reference frame to analyze their PSTs noticing skills and further develop their responsive teaching skills. We believe our study to have potential influence on both pre-service teacher training and professional development for in-service elementary teachers of science to leverage their noticing skills as essential to teaching responsively in science classrooms. PSTs enter the teacher training programs with beliefs and ideas (Pajares, 1992) about science, students, teaching and learning, and, more specifically, the teaching and learning of science that influence and impact their teaching practices (Bryan, 
2003; Eick \& Reed, 2002). It is essential that teacher educators consider PSTs' prior educational beliefs and ideas to be able to support development of prospective teachers' pedagogical knowledge and skills. Our study informs the educators of the novice teachers' ideas and noticing frames they use in science classrooms. This in turn will allow the educators to make informed decisions about training teachers to successfully train teachers to implement reform based instructional strategies in science as responsive teaching. Our study thus attempts to prepare teachers who can support the objectives of educational reforms towards creating scientifically literate individuals who can acquire scientific knowledge as well as understanding the nature and process of science.

\section{Conflicts of Interest}

The authors declare no conflicts of interest regarding the publication of this paper.

\section{References}

Ball, D. L. (2011). Foreword. In M. G. Sherin, V. R. Jacobs, \& R. Philipp (Eds.), Mathematics Teacher Noticing: Seeing Through Teachers' Eyes (pp. 20-22). New York, NY: Routledge. https://doi.org/10.1016/j.cppeds.2010.10.005

Ball, D. L., Thames, M., \& Phelps, G. (2008). Content Knowledge for Teaching: What Makes It Special? Journal of Teacher Education, 29, 389-407. https://doi.org/10.1177/0022487108324554

Benedict-Chambers, A., \& Aram, R. (2017). Tools for Teacher Noticing: Helping Preservice Teachers Notice and Analyze Student Thinking and Scientific Practice Use. Journal of Science Teacher Education, 28, 294-318. https://doi.org/10.1080/1046560X.2017.1302730

Berland, L. K., \& Reiser, B. J. (2009). Making Sense of Argumentation and Explanation. Science Education, 93, 26-55. https://doi.org/10.1002/sce.20286

Black, P. J., Harrison, C., Lee, C., Marshall, B., \& Wiliam, D. (2003). Assessment for learning: Putting It into Practice. London: Open University Press.

Borko, H., Jacobs, J., Eiteljorg, E., \& Pittman, M. E. (2008). Video as a Tool for Fostering Productive Discussions in Mathematics Professional Development. Teaching and Teacher Education, 24, 417-436. https://doi.org/10.1016/j.tate.2006.11.012

Bryan, L. A. (2003). Nestedness of Beliefs: Examining a Prospective Elementary Teacher's Belief System about Science Teaching and Learning. Journal of Research in Science Teaching, 40, 835-868. https://doi.org/10.1002/tea.10113

Coffey, J. E., Hammer, D., Levin, D. M., \& Grant, T. (2011). The Missing Disciplinary Substance of Formative Assessment. Journal of Research in Science Teaching, 48, 1109-1136. https://doi.org/10.1002/tea.20440

Covitt, B. A., Caplan, B. Z., \& Cano, A. (2018). Teachers' Use of Learning Progression Based Formative Assessment In water Instruction. Applied Measurement in Education, 31, 128-142.

Dalvi, T., \& Wendell, K. (2017). Using Student Video Cases to Assess Pre-service Elementary Teachers' Engineering Teaching Responsiveness. Research in Science Education, 47, 1101-1125. https://doi.org/10.1007/s11165-016-9547-5

Eick, C. J., \& Reed, C. J. (2002). What Makes an Inquiry-Oriented Science Teacher? The Influence of Learning Histories on Student Teacher Role Identity and Practice. Science 
Education, 86, 401-416. https://doi.org/10.1002/sce.10020

Furtak, E. M. (2012). Linking a Learning Progression for Natural Selection to Teachers' Enactment of Formative Assessment. Journal of Research in Science Teaching, 49, 1181-1210.

Furtak, E. M., \& Heredia, S. (2014). Exploring the Influence of Learning Progressions in two Teacher Communities. Journal of Research in Science Teaching, 51, 982-1020. https://doi.org/10.1002/tea.v51.8

Hammer, D. (1997). Discovery Learning and Discovery Teaching. Cognition and Instruction, 15, 485-529. https://doi.org/10.1207/s1532690xci1504_2

Hammer, D., Goldberg, F., \& Fargason, S. (2012). Responsive Teaching and the Beginnings of Energy in a Third Grade Classroom. Review of Science, Mathematics, and ICT Education, 6, 51-72.

Jaber, L. Z. (2014). Affective Dynamics of Students' Disciplinary Engagement in Science. Unpublished Doctoral Dissertation, Boston, MA: Tufts University.

Jacobs, V. R., Lamb, L. L., \& Philipp, R. A. (2010). Professional Noticing of Children's Mathematical Thinking. Journal for Research in Mathematics Education, 41, 169-202.

Knaggs, C. M., \& Sondergeld, T. A. (2015). Science as a Learner and as a Teacher: Measuring Science Self-Efficacy of Elementary Preservice Teachers. School Science and Mathematics, 115, 117-128. https://doi.org/10.1111/ssm.12110

Lampert, M., Franke, M. L., Kazemi, E., Ghousseini, H., Turrou, A. C., Beasley, H., Crowe, K. et al. (2013). Keeping It Complex: Using Rehearsals to Support Novice Teacher Learning of Ambitious Teaching. Journal of Teacher Education, 64, 226-243. https://doi.org/10.1177/0022487112473837

Levin, D. M., Hammer, D, Elby, A., \& Coffey, J. E. (2012). Becoming a Responsive Science Teacher: Focusing on Student Thinking in Secondary Science. Arlington, VA: NSTA Press.

Levin, D. M., Hammer, D., \& Coffey, J. E. (2009). Novice Teachers' Attention to Student Thinking. Journal of Teacher Education, 60, 142-154. https://doi.org/10.1177/0022487108330245

Luna, M. J., Selmer, S. J., \& Rye, J. A. (2018). Teachers' Noticing of Students' Thinking in Science through Classroom Artifacts: In What Ways Are Science and Engineering Practices Evident? Journal of Science Teacher Education, 29, 148-172.

Maskiewicz, A. C., \& Winters, V. A. (2012). Understanding the Co-Construction of Inquiry Practices: A Case Study of a Responsive Teaching Environment. Journal of Research in Science Teaching, 49, 429-464. https://doi.org/10.1002/tea.21007

McNeill, K. L. (2009). Teachers' Use of Curriculum to Support Students in Writing Scientific Arguments to Explain Phenomena. Science Education, 93, 233-268. https://doi.org/10.1002/sce.20294

Mitchell, R. N., \& Marin, K. A. (2015). Examining the Use of a Structured Analysis Framework to Support Prospective Teacher Noticing. Journal of Mathematics Teacher Education, 18, 551-575. https://doi.org/10.1007/s10857-014-9294-3

NGSS Lead States (2013). Next Generation Science Standards: For States, by States. http://www.nap.edu/catalog/18290/next-generation-science-standards-for-states-by-states

Pajares, M. F. (1992). Teachers' Beliefs and Educational Research: Cleaning up a Messy Construct. Review of Educational Research, 62, 307-332. https://doi.org/10.3102/00346543062003307

Robertson, A., Scherr, R., \& Hammer, D. (2015). Responsive Teaching in Science. New York: Routledge. https://doi.org/10.4324/9781315689302 
Schwarz, C. V., Passmore, C., \& Reiser, B. J. (2017). Helping Students Make Sense of the World Using Next Generation Science and Engineering Practices. Arlington, VA: NSTA Press.

Sherin, M. G. (2001). Developing a Professional Vision of Classroom Events. In T. Wood, B. S. Nelson, \& J. Warfield (Eds.), Beyond Classical Pedagogy: Teaching Elementary School Mathematics (pp. 75-93). Hillsdale, NJ: Erlbaum.

Sherin, M. G. (2007). The Development of Teachers' Professional Vision in Video Clubs. In R. Goldman, R. Pea, B. Barron, \& S. Derry (Eds.), Video Research in the Learning Sciences (pp. 383-395). Hillsdale, NJ: Erlbaum.

Sherin, M. G., \& Han, S. Y. (2004). Teacher Learning in the Context of a Video Club. Teaching and Teacher Education, 20, 163-183.

https://doi.org/10.1016/j.tate.2003.08.001

Sherin, M. G., \& Van Es, E. A. (2009). Effects of Video Club Participation on Teachers' Professional Vision. Journal of Teacher Education, 60, 20-37. https://doi.org/10.1177/0022487108328155

Star, J. R., \& Strickland, S. K. (2008). Learning to Observe: Using Video to Improve Preservice Mathematics Teachers' Ability to Notice. Journal of Mathematics Teacher Education, 11, 107-125. https://doi.org/10.1007/s10857-007-9063-7

Talanquer, V., Tomanek, D., \& Novodvorsky, I. (2013). Assessing Students' Understanding of Inquiry: What Do Prospective Science Teachers Notice? Journal of Research in Science Teaching, 50, 189-208.

Van Es, E. A. (2012). Examining the Development of a Teacher Learning Community: The Case of a Video Club. Teaching and Teacher Education, 28, 182-192. https://doi.org/10.1016/j.tate.2011.09.005

Van Es, E. A., \& Sherin, M. G. (2002). Learning to Notice: Scaffolding New Teachers' Interpretations of Classroom Interactions. Journal of Technology and Teacher Education, 10, 571-596.

Van Es, E. A., \& Sherin, M. G. (2008). Mathematics Teachers' "Learning to Notice" in the Context of a Video Club. Teaching and Teacher Education, 24, 244-276. https://doi.org/10.1016/j.tate.2006.11.005

Van Es, E. A., Cashen, M., Barnhart, T., \& Auger, A. (2017). Learning to Notice Mathematics Instruction: Using Video to Develop Preservice Teachers' Vision of Ambitions Pedagogy. Cognition and Instruction, 35, 1-23.

Van Es, E., \& Barnhart, T. (2015). Studying Teacher Noticing: Examining the Relationship among Pre-Service Science Teachers' Ability to Attend, Analyze and Respond to Student Thinking. Teaching and Teacher Education, 45, 83-93. https://doi.org/10.1016/j.tate.2014.09.005

Windschitl, M., Thompson, J., \& Braaten, M. (2011). Ambitious Pedagogy by Novice Teachers: Who Benefits from Tool-Supported Collaborative Inquiry into Practice and Why. Teachers College Record, 113, 1311-1360.

Zangori, L., Forbes, C. T., \& Biggers, M. (2013). Fostering Student Sensemaking in Elementary Science Learning Environments: Elementary Teachers' Use of Science Curriculum Materials to Promote Explanation Construction. Journal of Research in Science Teaching, 50, 989-1017. https://doi.org/10.1002/tea.21104 